ARTIGO

Recebido em: 15/06/2015

Aceito em: 08/01/2016

\title{
Educação a distância, bibliotecas polo e os recursos informacionais: uma pesquisa-ação ${ }^{1}$
}

\author{
Distance education, libraries polo and resources informational: a \\ research-action
}

\begin{abstract}
Maria Elizabeth de Oliveira COSTA
Mestre em Tecnologia e Gestão em EaD/UFRPE.- Bibliotecária-Documentalista do SB/UFMG mabethcosta@gmail.com
\end{abstract}

\section{Beatriz Valadares CENDóN}

Doutora em Ciência da Informação - Professora Titular Escola de Ciência da Informação/UFMG - cendon@eci.ufmg.br

\section{Resumo}

0 artigo trata da primeira parte da pesquisa que originou a dissertação intitulada "Educação a distância (EaD), bibliotecas polo e o acesso informacional" disponibilizado aos alunos dessa modalidade de ensino. Aborda as seguintes questões: como as Bibliotecas Universitárias e/ou os Sistemas de Bibliotecas - poderão apoiar as bibliotecas dos polos de apoio presencial, onde a instituição oferece cursos na modalidade a distância? Como oferecer o apoio e o acesso informacional científico aos alunos da EaD? Como assegurar que os alunos da EaD recebam os recursos informacionais necessários às suas atividades de pesquisa e extensão? Como procedimento metodológico a pesquisa consta de duas etapas sendo a primeira delas objeto deste artigo. 0 artigo relata a pesquisa realizada in loco nas bibliotecas dos polos com a finalidade de verificar os recursos informacionais que os alunos têm à sua disposição, comparando-os com a bibliografia básica dos cursos dessa modalidade. Pode-se concluir, por meio da análise e observação dos dados, que o material bibliográfico dos polos, comparado à bibliografia básica dos cursos, não atende às demandas necessárias dos usuários e ao ideal de uma biblioteca. A primeira parte deste estudo é também caracterizada como pesquisa-ação, e seus resultados foram apresentados à Instituição pesquisada.

Palavras-Chave: Educação a Distância (EaD). Biblioteca Polo de Apoio Presencial. Biblioteca Universitária, Universidade Federal de Minas Gerais (UFMG).

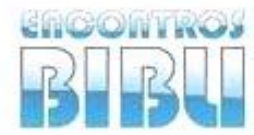

v. 21, n. 45,2016 p. $82-99$

ISSN 1518-2924
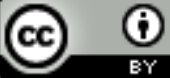

Esta obra está licenciada sob uma Licença Creative Commons.

1 Artigo baseado na primeira etapa da pesquisa de dissertação intitulada: Educação a distância, bibliotecas polo e o acesso informacional: um estudo de caso. 


\begin{abstract}
The research deals with the theme of Distance Education (DE), Polo Libraries and Information Resources available to students of distance education. The research is exploratory and uses both qualitative and quantitative approaches as methodological procedures to collect dada. It addresses the following questions: How the University Libraries could support the libraries in distance education poles? How to offer support and information access to distance education students? And how to ensure that distance education students receive the information resources required for their research activities? The methodology consisted of two phases, the first of which is the object of this article. The article reports the research conducted on-site in the polo libraries in order to verify the information resources that students have at their disposal, comparing them with the basic bibliography of this modality courses. Data shows that the bibliographies at the polos when compared to basic bibliography of the courses do not meet the required demands of users and the ideal of a library. The first part of this study is also characterized as research action, and its results have been presented to the institution.
\end{abstract}

Keywords: Distance Learning (DL). University Libraries. Polo's Support Classroom. Federal University of Minas Gerais (UFMG).

\title{
1 INTRODUÇÃO
}

A Educação a Distância (EaD) vem evoluindo ao longo dos anos. E assim sendo permite que o ensino chegue aos lugares mais remotos do país. Pode-se dizer que surgem novas oportunidades de estudo, conhecimento e cultura para aqueles que moram nas cidades do interior, longe dos centros urbanos. A EaD facilita a vida das pessoas que antes precisavam migrar para os grandes centros para entrar em uma universidade de alguma cidade brasileira e poder concluir os estudos.

No Brasil a transformação começou a partir de 2005, com a criação da Universidade Aberta do Brasil - UAB, com a ampliação do ensino na modalidade a distância nas várias regiões do país. A EaD, instituída pelo decreto $\mathrm{n}$ - 5.622, de 19 de dezembro de 2005, que regulamenta o art. 80 da Lei no 9.394, de 20 de dezembro de 1996, da Lei de Diretrizes e Bases da Educação (LDB), se estabelece com normas e diretrizes, e, a partir deste Decreto, caracteriza-se a educação a distância "como modalidade educacional na qual a mediação didático-pedagógica nos processos de ensino e aprendizagem ocorre com a utilização de meios e tecnologias de informação e comunicação." (BRASIL/MEC, 2007).

A modalidade de ensino a distância passa a contemplar também a prática cotidiana das pessoas, levando em conta que o mercado de trabalho em mudanças constantes, impulsionado pela necessidade de mão de obra especializada, também busca pessoas com competência. E assim surgem os cursos de capacitação, aperfeiçoamento e especialização a distância, fazendo com que as pessoas se qualifiquem por meio da EaD.

A expansão da Educação Superior no Brasil conta, também, com o Programa de Apoio a Planos de Reestruturação e Expansão das Universidades Federais (REUNI), do Governo Federal, que tem como principal objetivo ampliar o acesso e a permanência dos alunos na Educação Superior.

Para que a EaD obtenha êxito total na sua função é necessário que Órgãos Institucionais Federais, Estaduais, Municipais e as Instituições de 
Ensino Superior, dentro da competência de cada, se unam em objetivos maiores: o usuário, o cidadão e os recursos informacionais necessários à disposição dos mesmos.

\section{BIBLIOTECAS DOS POLOS DE APOIO PRESENCIAL}

O Ministério da Educação e Cultura (MEC), através do decreto 5.800, de 8 julho de 2006, ao implantar a UAB institui um acordo de cooperação técnica entre o Ministério da Educação, as universidades públicas federais e estaduais, e, os Institutos Federais de educação formando assim o Sistema UAB, que por sua vez, enfatiza a articulação das instituições públicas de ensino superior com os polos de apoio presencial destinados a apoiar de modo descentralizado as atividades pedagógicas e administrativas relativas aos cursos e programas.

Os polos de apoio presencial para EaD são considerados a "extensão das universidades". Desse modo estabelece que os polos devem: ser a sede dos momentos presenciais descentralizados, ter estágios supervisionados, oferecer práticas em laboratórios de ensino e contar com tutorias presenciais. Além disso, os polos precisam contar, com uma infraestrutura de salas de aulas, auditórios, laboratórios e bibliotecas. (BRASIL, 2006).

O MEC é a instituição que "firma os acordos de cooperação técnica ou convênios com os entes federativos interessados em manter os polos de apoio presencial do Sistema UAB" e para que a EaD cumpra seu papel no País, apresenta um documento com a definição de Referenciais de Qualidade para a EaD, no País.

Esses Referenciais de Qualidade circunscrevem-se no ordenamento legal vigente em complemento às determinações específicas da Lei de Diretrizes e Bases da Educação, do Decreto 5.622, de dezembro de 2005, do Decreto 5.773 de junho de 2006 e das Portarias Normativas 1 e 2 , de 11 de janeiro de2007, (BRASIL, 2007)

Assim através desse documento "Referenciais de Qualidade para Educação Superior a Distância" em relação às bibliotecas, estabelece critérios quando diz que nos cursos a distância, os polos devem ter em sua infraestrutura uma biblioteca contendo:

[...] "um acervo mínimo para possibilitar acesso dos estudantes à bibliografia, além de material instrucional do curso; empréstimo de livros e periódicos atualizados ligados as IES para possibilitar acesso à bibliografia do curso, além do disponibilizado no polo" (BRASIL/MEC, 2007, p. 19).

Ainda de acordo com o decreto no 5.622, de 19 de dezembro de 2005, art. 12, os polos devem ter "bibliotecas adequadas, inclusive com acervo eletrônico remoto e acesso por meio de redes de comunicação e sistemas de informação, com regime de funcionamento e atendimento adequados aos estudantes da educação a distância." (BRASIL, 2005)

Portanto, é necessário por parte das instituições que oferecem o ensino a distância um envolvimento maior no sentido de prover esses 
usuários de condições necessárias para desenvolvimento de suas atividades acadêmicas. De acordo com Ferrugini (2014) "uma das fragilidades apontada em relação à Educação a Distância que impede a maior qualidade dos cursos e a construção de novos conhecimentos é a falta de acervo impresso de qualidade disponível para os alunos nos polos de apoio presencial".

Litto (2010, p. 18) corrobora com Ferrugini, quando diz que "enquanto em muitos países os alunos que estudam a distância têm ao seu dispor livros universitários (com 150 paginas ou mais) para leituras durante o curso, no Brasil instalou-se a prática de fornecer ao aluno apenas uma "apostila" ou resumo dos pontos principais da matéria".

Garcez e Rados (2002) enfatizam em seu estudo que a biblioteca física ainda é o meio de informação e busca de conhecimento mais utilizado pelos alunos. A não disponibilização de bibliotecas dificulta a aprendizagem na medida em que os alunos ficam restritos às apostilas e alguns materiais disponibilizados pelos professores/ tutores na plataforma virtual de ensino aprendizagem.

Assim sendo é necessário que as Instituições Federais de Ensino Superior - IFES, através de suas Bibliotecas Universitárias ou Sistema de Bibliotecas empreendam essa infraestrutura das bibliotecas presenciais no apoio técnico científico as bibliotecas dos polos, onde a instituição oferece os cursos na modalidade a distância.

Diante disso, esta pesquisa versa sobre o ensino a distância, as bibliotecas dos polos de apoio presencial e o acesso aos recursos informacionais, tais como livros, periódicos e outros materiais bibliográficos, disponíveis nas bibliotecas dos polos da EaD. "A Educação a distância é tão ou mais complexa que o ensino presencial e para que ela tenha qualidade, precisa ser organizada desde a sua proposta até a sua prática" (KONRATH; TAROUCO; BEHAR, 2001).

As questões abordadas no corrente estudo são as seguintes: (1) Como as Bibliotecas Universitárias e/ou os Sistemas de Bibliotecas - poderão apoiar as bibliotecas dos polos de apoio presenciais, onde a instituição oferece cursos na modalidade a distância?; (2) Como oferecer o apoio e o acesso informacional científico aos alunos da EaD?; (3) Como assegurar que os alunos da EaD recebam os recursos informacionais necessários às suas atividades de pesquisa e extensão?

De acordo com Macedo e Modesto (1999, p. 49), a biblioteca universitária tem como missão a capacitação do estudante [...] conscientizando-os do uso correto dos recursos informacionais e dos princípios da pesquisa bibliográfica no sentido de torná-los "usuários da informação".

\section{PROCEDIMENTOS METODOLÓGICOS}

Apresenta-se a seguir, a caracterização da pesquisa, do universo estudado e do instrumento de coleta de dados.

A pesquisa é de cunho social. "Na pesquisa social, a metodologia é muito importante por se constituir na delimitação do caminho e das práticas utilizadas na abordagem da realidade investigada. Inclui as teorias, as 
concepções teóricas, os métodos e as técnicas, mas também a criatividade do investigador" (MINAYO, 1994, p. 16).

Com relação à natureza esta é uma pesquisa-ação que "surgiu da necessidade de superar a lacuna entre teoria e prática. Uma das características deste tipo de pesquisa é que através dela se procura intervir na prática de modo inovador já no decorrer do próprio processo de pesquisa [...]" (KETELE; ROEGIERS, 1993 apud ENGEL, 2000, p. 182).

Do ponto de vista dos objetivos, trata-se de uma pesquisa exploratória. Para Duarte, "a pesquisa exploratória permite uma maior familiaridade entre o pesquisador e o tema pesquisado, visto que este ainda é pouco conhecido, pouco explorado" (DUARTE, [2013?], on-line).

Quanto aos procedimentos metodológicos adotados, a pesquisa pode ser classificada como um estudo de caso, que por sua vez, caracteriza-se por ter como objeto de estudo uma ou mais unidades que são analisadas para fornecer conhecimento aprofundado da realidade do ambiente estudado que poderão ser aplicados em outras unidades. Nesse caso, o pesquisador pode utilizar de vários instrumentos, tais como, entrevistas, observação direta e questionários para coletar os dados e informações e desenvolver a pesquisa.

A abordagem do problema utilizada para a pesquisa englobou o método qualitativo (entrevista, observação direta), pois nos resultados abordam procedimentos estatísticos, descrição e apresentação dos dados e análises.

\subsection{0 espaço e tempo da pesquisa}

O espaço delimitado para a pesquisa foi a Universidade Federal de Minas Gerais (UFMG), os polos de apoio presencial, onde a instituição oferece a modalidade de Educação a Distância e mais especificamente as Bibliotecas dos Polos. 0 foco da pesquisa é o uso e o Acesso aos Recursos Informacionais, que o aluno da $\mathrm{EaD}$ tem à sua disposição. A pesquisa seguiu o seguinte percurso:

- $\quad$ Realização de visitas técnicas, a partir de um diagnóstico da realidade das bibliotecas dos polos, definidas para a pesquisa, situadas nos diferentes municípios do Estado de Minas Gerais. Assim, foram realizadas as seguintes fases:

- Observação dos fatos;

- Coleta de dados sobre o acervo disponibilizado na biblioteca polo;

- Informações sobre o acervo bibliográfico solicitado na bibliografia básica dos cursos da modalidade a distância;

- Informação sobre o acervo bibliográfico disponibilizado pelo Sistema de Bibliotecas (SB/UFMG).

Para a pesquisa nas bibliotecas dos polos foi selecionada uma amostra de cinco polos, dentre os 14 que oferecem cursos de graduação (licenciatura e bacharelado), na UFMG. Os cinco polos são das cidades de Bom Despacho, Buritis, Formiga, Montes Claros e Governador Valadares, conforme demonstrado na tabela 1. 
Tabela 1: Polos visitados $x$ Quantidade de alunos

\begin{tabular}{lc}
\hline Polos visitados & Quantidade de alunos por polo \\
\hline Bom Despacho & 76 \\
Buritis & 69 \\
Formiga & 201 \\
Governador Valadares & 545 \\
Montes Claros & 331 \\
\hline Total & $\mathbf{1 2 2 2}$
\end{tabular}

Fonte: Dados da pesquisa, 2013.

$\mathrm{Na}$ primeira etapa desta pesquisa, que teve como foco os polos de apoio presencial da $\mathrm{EaD}$, foi realizada uma pesquisa in loco nas bibliotecas com a finalidade de verificar: o serviço e recursos informacionais que os alunos têm à sua disposição; se as bibliotecas possuem o acervo contido nas bibliografias básicas dos cursos; e se são oferecidos acesso as fontes informacionais e serviços como: acervos das bibliotecas digitais, acesso à fonte de informação virtual como, por exemplo, o acesso ao Portal de Periódicos da Capes, a Biblioteca Digital de Teses e Dissertações do IBICT, e os acervos automatizados.

A pesquisadora em sua atuação na Gestão de uma Biblioteca Universitária - Sistema de Bibliotecas - idealizou, planejou e criou na estrutura organizacional da Biblioteca Universitária o Setor de Apoio às Bibliotecas Polos da Educação a Distância, aprovado pelas instâncias deliberativas. A pesquisa contou também com o apoio do Centro de Apoio a Educação a Distância (CAED) da Instituição principalmente no que tange às visitas aos polos de apoio à educação a distância. Para a visita nos polos, a pesquisadora atuava junto com pessoal do Setor de Apoio às Bibliotecas Polo na coleta de informações e dados, visando também o aprimoramento do Setor. Esta etapa deste estudo é caracterizada como pesquisa-ação, e seus resultados apresentados aos órgãos da Instituição. A pesquisa ação é aquela que:

[...] procura unir a pesquisa à ação ou prática, isto é, desenvolver o conhecimento e a compreensão como parte da prática. É, portanto, uma maneira de se fazer pesquisa em situações em que também se é uma pessoa da prática e se deseja melhorar a compreensão desta (KETELE; ROEGIERS, 1993, apud ENGEL, 2000, p. 182).

De acordo com Tozoni-Reis (2007) que reconhece a pesquisa-ação como uma modalidade de pesquisa que coloca a ciência a serviço da emancipação social, com duplo desafio, o de pesquisar e participar, o de investigar e educar, de modo a articular a teoria e a prática. Trip (2005) corrobora com esta ao afirmar que:

É importante que se reconheça a pesquisa-ação como um dos inúmeros tipos de investigação-ação, que é um termo genérico para qualquer processo que siga um ciclo no qual se aprimora a prática pela oscilação sistemática entre agir 
no campo da prática e investiga a respeito dela. Planeja-se, programa-se, descreve-se e avalia-se uma mudança para melhora de sua prática, aprendendo mais, no correr do processo, tanto a respeito da prática quanto da própria investigação. A maioria dos processos de melhora segue o mesmo ciclo. A solução de problemas, por exemplo, começa com a identificação do problema o planejamento de uma solução, sua implementação, seu monitoramento e a avaliação de sua eficácia [...] (TRIP, 2005, p. 445).

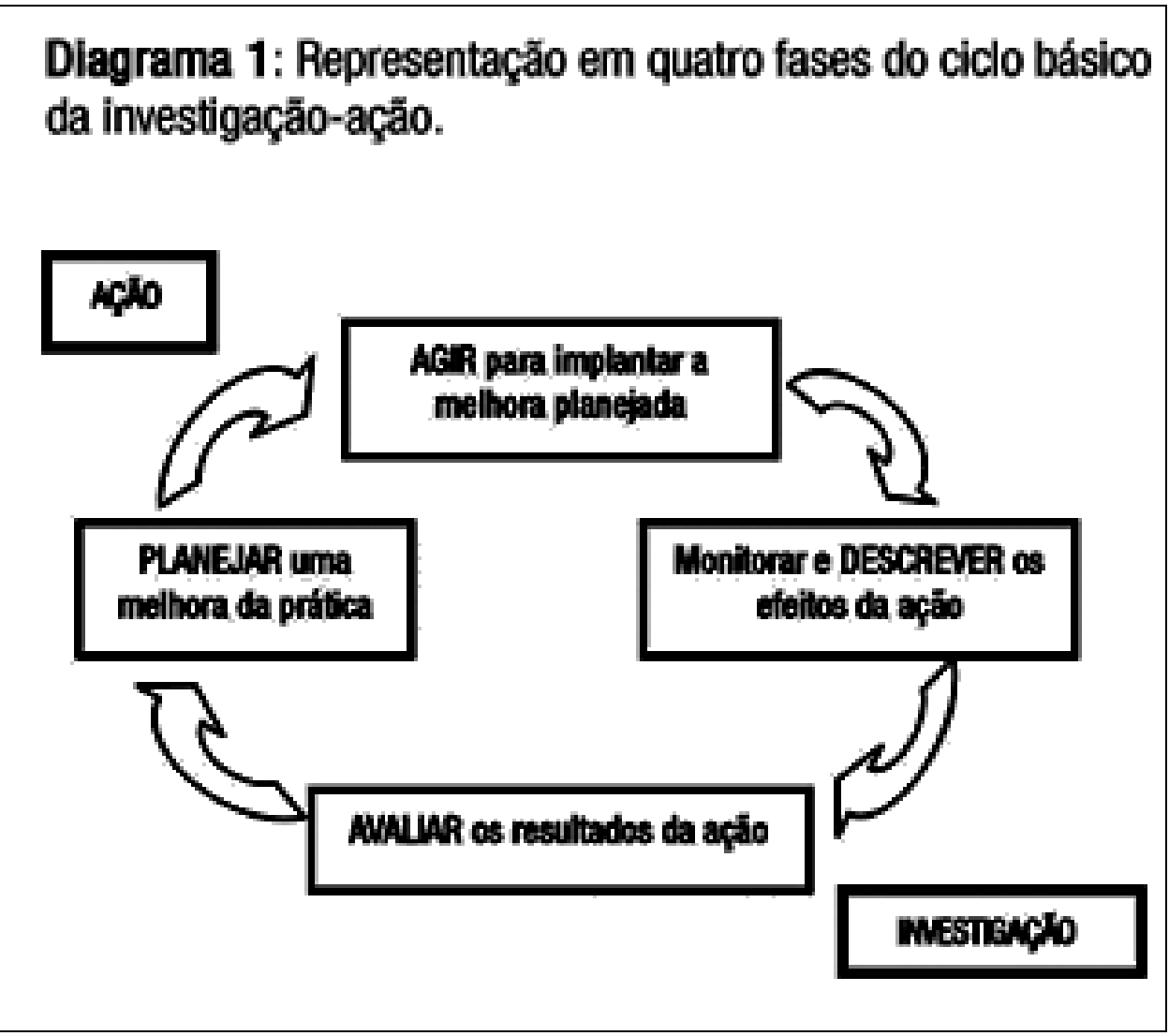

Figura 1: Ciclo da pesquisa-ação

Fonte: Trip (2005).

Para a pesquisa-ação, diferentemente dos modelos mais tradicionais, o pressuposto elementar desta é a participação do pesquisador na situação pesquisada. É um tipo de pesquisa voltada para o social. Assim, Mendes (2008, p. 59) complementa com "o fato de a pesquisa-ação não almejar somente a descrição, o diagnóstico ou a mera compreensão da prática, mas também visar à transformação desta". 


\section{RESULTADOS E ANÁLISE DOS DADOS}

Esta pesquisa consta de duas etapas ${ }^{2}$. Na primeira etapa, objeto deste artigo, foi realizado as seguintes fases:

(a) visita a cinco bibliotecas dos polos objetivando um diagnóstico dos recursos informacionais que o usuário da $\mathrm{EaD}$ tem à sua disposição;

(b) comparação do acervo bibliográfico existente em cada biblioteca do polo com a bibliografia básica indicada pela instituição;

(c) análise da bibliografia básica dos cursos da EaD, via comparação com o acervo existente nas bibliotecas do SB/UFMG.

O objetivo dessas análises é verificar o que as bibliotecas dos polos possuem e como a Biblioteca Universitária (BU), enquanto órgão gerenciador das 25 bibliotecas do SB/UFMG poderia oferecer em relação aos serviços e produtos já existentes no SB/UFMG aos alunos da modalidade a distância que frequentam as bibliotecas dos polos de apoio presencial. Em seguida foi realizado um levantamento para identificar o acervo existente nas bibliotecas dos polos, em comparação com o acervo da bibliografia básica dos cursos na modalidade a distância. E a comparação entre o material informacional das bibliografias básicas dos cursos EaD e os livros existentes no SB/ UFMG.

\subsection{Comparação do acervo nas bibliotecas dos Polos e a bibliografia básica indicadas nos cursos}

As bibliotecas dos polos de apoio presencial precisam ter um acervo compatível com a bibliografia básica dos cursos para apoio as atividades acadêmicas científicas aos alunos dessa modalidade.

Pela análise e observância dos fatos, em relação ao acervo existente nas bibliotecas dos polos e a bibliografia básica dos cursos EaD, conforme descrito na Tabela 2 pode-se diagnosticar o seguinte:


em outro artigo 
Tabela 2: Acervos das bibliotecas dos polos pesquisados

\begin{tabular}{|c|c|c|c|c|c|c|}
\hline \multirow{2}{*}{$\begin{array}{l}\text { Polos de } \\
\text { Apoio } \\
\text { Presencial }\end{array}$} & \multirow[t]{2}{*}{ Cursos } & \multicolumn{2}{|c|}{$\begin{array}{l}\text { Livros } \\
\text { disponibilizados } \\
\text { pelo polo }\end{array}$} & \multicolumn{2}{|c|}{$\begin{array}{l}\text { Livros não } \\
\text { disponibilizados } \\
\text { pelo polo }\end{array}$} & $\begin{array}{l}\text { Livros da } \\
\text { bibliografia } \\
\text { básica e } \\
\text { complementar }\end{array}$ \\
\hline & & $\begin{array}{c}\text { Valores } \\
\text { absolutos }\end{array}$ & $\%$ & $\begin{array}{c}\text { Valores } \\
\text { absolutos }\end{array}$ & $\%$ & TOTAL \\
\hline \multirow{2}{*}{$\begin{array}{l}\text { Bom } \\
\text { Despacho }\end{array}$} & Matemática & 0 & 0 & 86 & 100 & 86 \\
\hline & Pedagogia & 181 & 76,1 & 57 & 23,9 & 238 \\
\hline Buritis & Pedagogia & 12 & 5 & 226 & 95 & 238 \\
\hline \multirow{2}{*}{ Formiga } & Geografia & 38 & 4,5 & 837 & 95,7 & 875 \\
\hline & Pedagogia & 214 & 89,9 & 24 & 10,1 & 238 \\
\hline \multirow{4}{*}{$\begin{array}{l}\text { Governador } \\
\text { Valadares }\end{array}$} & $\begin{array}{l}\text { Ciências } \\
\text { Biológicas }\end{array}$ & 30 & 15,1 & 169 & 84,9 & 199 \\
\hline & Matemática & 8 & 9,3 & 78 & 90,7 & 86 \\
\hline & Pedagogia & 19 & 62,6 & 89 & 37,4 & 238 \\
\hline & Química & 50 & 24,9 & 151 & 75,1 & 201 \\
\hline \multirow{3}{*}{ Montes Claros } & $\begin{array}{l}\text { Ciências } \\
\text { Biológicas }\end{array}$ & 35 & 17,6 & 164 & 82,4 & 199 \\
\hline & Matemática & 9 & 10,5 & 77 & 89,5 & 86 \\
\hline & Química & 58 & 28,9 & 143 & 71,1 & 201 \\
\hline
\end{tabular}

Fonte: Dados da pesquisa, 2013.

O polo do município de Bom Despacho oferece, pela UFMG, os cursos de graduação em Matemática e Pedagogia. Ao analisar o acervo existente na biblioteca do polo de Bom Despacho e compará-lo com a bibliografia básica do curso, percebeu-se, conforme aponta a tabela 2, e, especificamente em relação à Matemática, que o acervo praticamente inexiste. Cabe destacar que o curso estava em formação na época.

0 polo de Buritis possui, pela UFMG, o curso de graduação em Pedagogia. Os dados verificados em relação ao acervo bibliográfico existente no polo e o solicitado pela bibliografia básica dos cursos, existem cerca de 5\% do acervo. Cabe ressaltar que os alunos do curso de Pedagogia utilizam as apostilas dos cursos. Esse fato foi confirmado pelo "estudo de usuários" realizado junto aos alunos da modalidade EaD.

No polo de Formiga são ofertados, pela UFMG, cursos de graduação em Geografia e Pedagogia. Apresentam a seguinte situação no que se refere aos acervos existentes no referido polo: Pedagogia possui $89,9 \%$ do acervo indicado na bibliografia básica do curso, enquanto o curso de Geografia possui $4,3 \%$ do acervo. Pela análise pode-se inferir que o acervo que se encontra na biblioteca do polo, referente ao curso de Geografia, não atende ao material solicitado na bibliografia básica do curso.

O polo de Governador Valadares atende pela UFMG os cursos de Ciências Biológicas, Matemática, Pedagogia e Química. E assim apresentam o acervo disponibilizado pela biblioteca polo de Governador Valadares em relação à bibliografia básica dos cursos: 15,6\% do acervo de Ciências Biológicas; 9,3\% de Matemática; 62,6\% de Pedagogia; e Química 24,9\%. Pode-se inferir que há um baixo percentual de materiais bibliográficos na biblioteca polo, referente ao curso de Ciências Biológicas, Matemática e Química. 0 acervo do curso de Pedagogia possui mais 60\% do solicitado na 
bibliografia básica. A bibliografia do curso de Pedagogia tem livros, apostilas em volumes produzidos pela Faculdade de Educação (FaE), da UFMG.

O polo UAB de Montes Claros atende pela UFMG, os cursos em Ciências Biológicas, Matemática e Química. Os dados comprovam que o acervo da biblioteca do polo de Montes Claros, em relação ao curso de Ciências Biológicas corresponde a 17,6\%; o acervo de Matemática, 10,5\%; e o acervo de Química corresponde a 28,8\% da bibliografia básica do curso. Assim, pode-se inferir que a coleção da biblioteca do polo de Montes Claros, em relação à bibliografia básica dos cursos, tem baixo percentual de recursos informacionais.

De acordo com os dados coletados, com exceção do acervo de Pedagogia, há baixo percentual de acervos bibliográficos nas bibliotecas dos polos, principalmente relacionado ao material bibliográfico indicado nas bibliografias básicas dos cursos. Garcez e Rados (2002, p. 23) afirmam que "os bens e serviços bibliotecários devem constar no planejamento dos cursos a distância e estarem disponíveis de maneira compatível com as necessidades dos seus usuários".

\subsection{Comparação entre o material informacional das bibliografias básicas dos cursos EaD e os livros existentes no SB/UFMG}

A UFMG, além dos cursos de graduação na modalidade a distância, oferece também (não sendo objeto desta pesquisa) cursos de especialização, aperfeiçoamento e atualização na modalidade a distância. E possui um acervo com mais de 1 (um) milhão de itens de material bibliográfico em suas bibliotecas campus que compõem o SB/UFMG. De acordo com Costa et. al. (2012, p. 9), é preciso:

[...] disponibilizar o acervo e os serviços prestados pelas 25 bibliotecas dos cursos presenciais da Universidade, o que possibilitará aos alunos da ampliar o acesso a diferentes fontes de informação, além das já existentes nas bibliotecas polo. Pretende-se também, como resultados, oferecer e criar condições de acesso para a utilização dos diferentes tipos de documentos (formatos tradicional, digital e eletrônico); proporcionar, à equipe das bibliotecas polo, orientação e treinamento no uso das ferramentas de informação disponibilizadas pelo SB/UFMG para que tenha domínio das mesmas e saiba orientar os alunos da EaD; assim como criar tutoriais de alguns sistemas informacionais oferecidos pelo SB/UFMG, [...]

Tabela 3:Comparativo entre a bibliografia básica dos cursos EaD e os existentes no SB/UFMG

\begin{tabular}{lcccc}
\hline \multirow{2}{*}{ CURSOS } & \multicolumn{2}{l}{$\begin{array}{l}\text { Livros disponibilizados pelo } \\
\text { SB/UFMG }\end{array}$} & $\%$ & Vivros não disponibilizados \\
& Velo SB/UFMG & \\
\cline { 2 - 5 } Ciências Biológicas & 166 & 83,4 & 33 & 16,6 \\
Geografia & 642 & 73,4 & 233 & 26,6 \\
Matemática & 31 & 36 & 55 & 64 \\
Pedagogia & 230 & 96,6 & 8 & 3,4 \\
Química & 92 & 71,3 & 37 & 28,7 \\
\hline
\end{tabular}

Fonte: Dados da pesquisa, 2013. 
No SB/UFMG, com relação aos livros indicados nas bibliografias básicas dos cursos EaD, observou-se: 83,4\% dos livros da bibliografia básica do curso de Ciências Biológicas; 79,9\% do curso de Geografia; 36\% do curso de Matemática; 96,6 \% do curso de Pedagogia; 71,3\% do curso de Química existem no SB/UFMG, conforme descrito no gráfico 1.

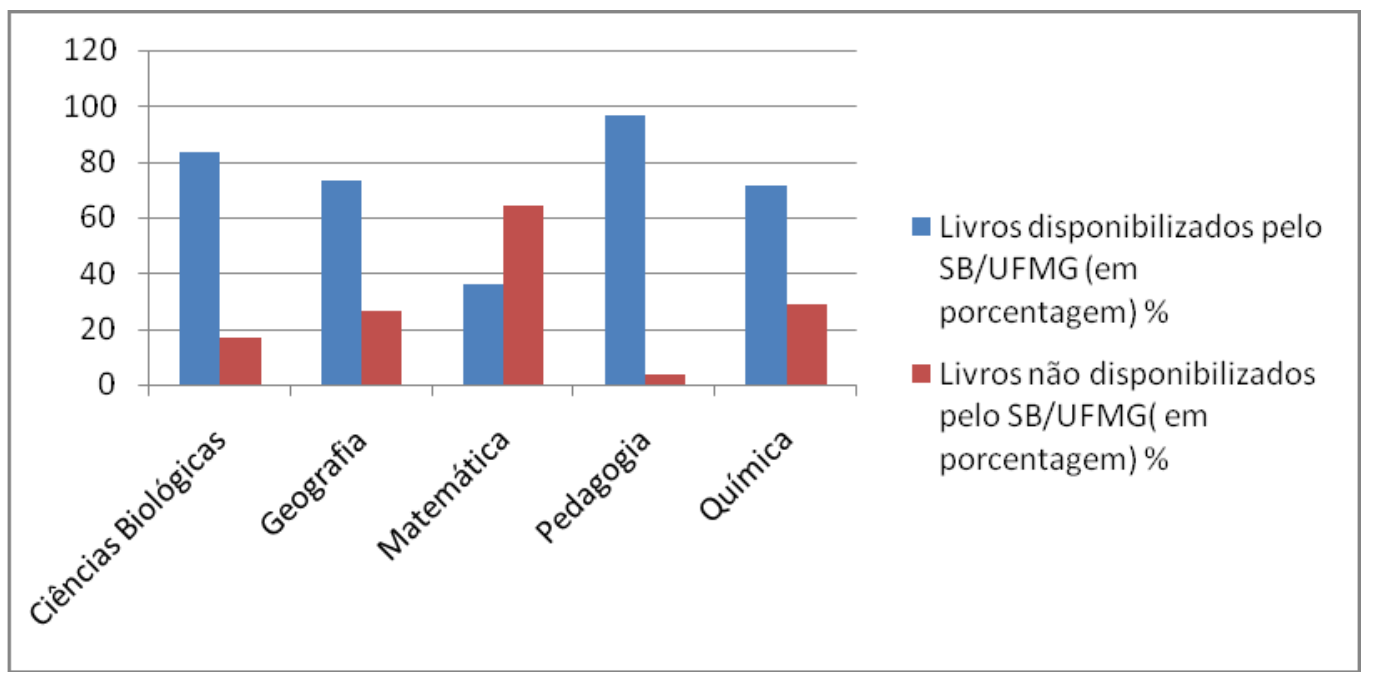

Gráfico 1: Análise dos livros disponibilizados no SB/UFMG em relação à bibliografia básica e complementar dos cursos em EaD/UFMG, em porcentagem.

Fonte: Dados da pesquisa 2013.

De acordo com o gráfico 2, pode-se inferir que no SB/UFMG, com exceção do curso de Matemática, que a maioria dos livros indicados na bibliografia básica ou programas de ensino dos cursos na modalidade a distância, existem nas bibliotecas do SB/ UFMG.

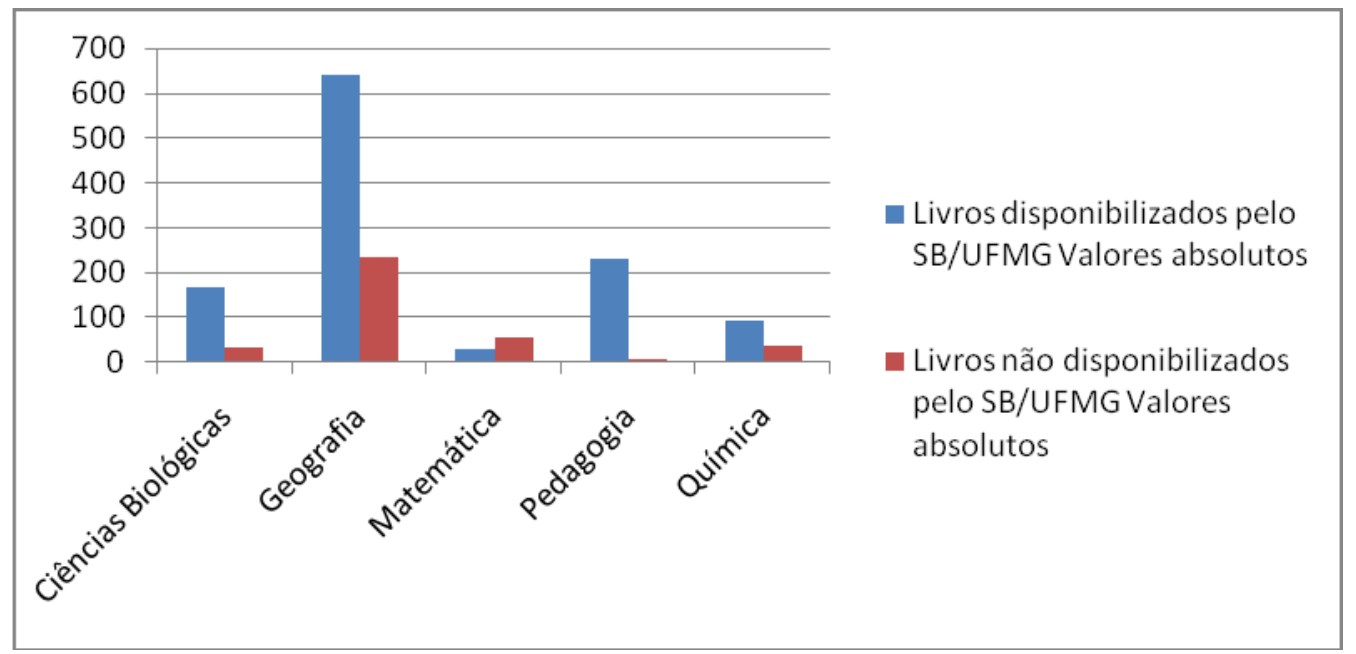

Gráfico 2: Análise dos livros disponibilizados no SB/UFMG em relação a bibliografia básica e complementar dos cursos em EaD/UFMG, em valores absolutos.

Fonte: Dados da pesquisa 2013.

Assim, cabe ressaltar a necessidade de uma interação entre as bibliotecas universitárias e/ou sistema de bibliotecas e, ainda, os órgãos gerenciadores dessas estruturas, com as bibliotecas dos polos de apoio presencial e vice-versa, para que esse alunato da EaD tenha acesso e uso dos 
recursos informacionais necessários para suas atividades de pesquisa acadêmico-científica.

\subsection{Pesquisa-ação e algumas diretrizes}

Assim, dentro da perspectiva da pesquisa-ação, que, de acordo com Trip (2005), "visa melhorar a prática", conforme citado, os resultados, ainda durante a pesquisa foram apresentados à instituição, sendo algumas diretrizes advindas dos resultados da pesquisa construídas e implementadas pelos órgãos e setores da instituição ${ }^{3}$. Alguns exemplos são:

(a) Estudos sobre como o acervo do Sistema de Bibliotecas, deveria ser estendido aos alunos da modalidade a distância nos polos, considerando que havia mais de uma instituição oferecendo cursos nos respectivos polos;

(b) Políticas ${ }^{4}$ e normas (em desenvolvimento) para empréstimo dos livros e oferecimento de outros serviços informacionais, aos alunos da modalidade EaD levando em conta o localização geográfica, entre o SB/UFMG e as bibliotecas dos polos de apoio presencial nos interiores do Estado;

(c) Treinamentos ${ }^{5}$ para os coordenadores e tutores dos respectivos polos para receberem e transmitirem informações aos alunos da modalidade a distância sobre como acessar os recursos informacionais já existentes no SB/UFMG (presencial);

(d) Treinamento para a comunidade da EaD sobre como acessar o Portal de Periódicos da Capes;

(e) Tutorial ${ }^{6}$ de como acessar a base de gerenciamento do acervo bibliográfico (software pergamun) do SB/UFMG, construído em parceria entre, BU, CAED e Escola de Belas Artes;

(f) Confecção e entrega pelo Setor de Apoio às Bibliotecas Polo da BU das "carteiras de usuários do Sistema de Bibliotecas" aos alunos da EaD. Conforme Costa (2015, p. 53) alunos dessa modalidade desconhecem serviços e produtos que podem ser oferecidos a eles;

(g) Criação de um tutorial sobre como acessar o Portal da Capes e ter o acesso a essa fonte de informação, sendo o tutorial específico para os alunos dessa modalidade.

(h) Proposta de criação de uma Biblioteca virtual com material referente as bibliografias básicas dos cursos da EaD.

De acordo com Blattmann

Para sanar o problema de acervo impresso, bibliotecas virtuais ou eletrônicas eficientes e com grande quantidade de títulos/acervo seria uma opção mais acessível para atender à demanda dos estudantes que se encontram longe de seu respectivo polo (BLATTMANN, 2001).

\footnotetext{
3 Biblioteca Universitária (BU/UFMG) e o Centro de Apoio a Educação a Distância (CAED/UFMG); BU-Setor de Apoio às Bibliotecas Polos da EaD e-Setor de Apoio aos Usuários do Portal da Capes na UFMG.

4 Em análise pelo Grupo de Estudo (circulação) da BU-SB/UFMG, e Setor de Apoio as Bibliotecas Polos da BU, na época.

${ }^{5}$ Evento realizado pela BU e CAED com coordenadores e tutores dos Polos.

${ }^{6}$ No sitio: www.bu.ufmg.br (Catalogo online)
} 
Os resultados obtidos com a pesquisa-ação foram relevantes e contribuíram para a elucidação das questões referentes ao acesso e uso das fontes de informação disponibilizadas para os alunos da EaD na UFMG. Com os dados foram possíveis à implementação de ações de desenvolvimento institucional com base nas evidências científicas obtidas.

\title{
5 CONSIDERAÇÕES FINAIS E RECOMENDAÇÕES
}

A pesquisadora já havia identificado a necessidade de um maior envolvimento, interação e apoio entre as Bibliotecas Universitárias e as bibliotecas dos polos de apoio presencial dos cursos a distância, e seus usuários.

$\mathrm{Na}$ Ciência da Informação, há grupos científicos de pesquisas direcionados ao estudo das bibliotecas universitárias, públicas, escolares, além das especializadas, serviços de recuperação da informação, informação científica, e outros estudos afins. Entretanto, sobre as bibliotecas dos polos de apoio presencial, não há grupos de pesquisa na instituição, e percebe-se a escassez de publicação na literatura sobre esse tema.

A American Library Association (ALA), em uma das suas subdivisões, a Association of College \& Research Libraries, nas suas diretrizes, e de acordo com o documento Guidelines for Distance Learning Library Services, recomenda que as instituições que promovem educação a distância devem ser planejadas e geridas, a fim de possibilitar o suprimento das necessidades informacionais e bibliográficas para o corpo discente.

Seguindo estas recomendações, a pesquisadora, que atua nas áreas de Biblioteconomia e Ciência da Informação e, na época, como gestora de um Sistema de Bibliotecas, idealizou o Setor de Apoio as Bibliotecas Polo da EaD que, após aprovação no órgão colegiado da unidade, foi implantado, visando apoio ao acesso e uso dos recursos informacionais para os alunos dessa modalidade de ensino na Instituição. E enquanto mestranda direcionou sua pesquisa para o Ensino a Distância e as Bibliotecas dos Polos de Apoio Presencial. Dessa forma, busca transformar a teoria à prática e a prática em ação, e faz da pesquisa, além de outras características, uma pesquisa-ação. Em uma pesquisa como esta, e de acordo com Franco (2005),

\begin{abstract}
a pesquisa-ação assume uma postura diferenciada diante do conhecimento, uma vez que busca, ao mesmo tempo, conhecer e intervir na realidade que pesquisa. Essa imbricação entre pesquisa e ação faz com que o pesquisador, inevitavelmente, faça parte do universo pesquisado, o que, de alguma forma, anula a possibilidade de uma postura de neutralidade (FRANCO, 2005, p. 490).
\end{abstract}

A presente pesquisa envolveu outros processos de uma metodologia científica, tanto formais como informais. Fez-se um levantamento bibliográfico sobre a $\mathrm{EaD}$ e a área da Biblioteconomia e seus afins, para embasar o referencial teórico e o próprio dissertar sobre os assuntos. A pesquisa tem característica social. 
Assim, conforme a metodologia proposta foi realizado o diagnóstico nas bibliotecas dos polos de apoio nas cidades escolhidas para a pesquisa, pois buscou-se conhecer de perto os polos de apoio presencial e verificar os recursos, os serviços e os produtos informacionais oferecidos aos alunos, assim como fazer uma comparação entre a bibliografia básica e complementar dos cursos da EaD e o material informacional disponibilizado nas bibliotecas dos polos. Para a pesquisa, limitou-se, a cinco polos. Ao conhecer as bibliotecas dos polos, teve-se uma compreensão da realidade investigada.

Por meio de observação direta e contatos pessoais nos polos, teve-se uma compreensão da realidade investigada, aplicando assim o método da pesquisa qualitativa, que é usado quando se tem como objetivo analisar "a subjetividade, valores e crenças que orientam as ações humanas, o que interessa é a natureza das respostas, dos sentimentos, das opiniões, das crenças; não o quanto, mas aquilo que as pessoas sentem, pensam, opinam, valorizam" (GIL, 2002, p. 72).

Pode-se inferir, pelos dados apresentados, com exceção do acervo de Pedagogia, que há baixo percentual de acervos bibliográficos nas bibliotecas dos polos, principalmente relacionado às bibliografias básicas dos cursos. No que se refere ao acervo de Pedagogia, as apostilas são muito utilizadas, sendo esses dados confirmados pelo "estudo de usuários" realizado junto aos alunos na da EaD, em outro momento da pesquisa. "A UFMG, por meio da Faculdade de Educação (FaE) - projeto da Cátedra UNESCO tem como uma das iniciativas a responsabilidade pela produção de materiais didáticos para EaD em diversos suportes e linguagens" (TARQUINIO, 2012, p. 135). 0 curso de Pedagogia possui apostilas produzidas pela Instituição, que fazem parte da bibliografia básica.

Nesta etapa, pode-se concluir, em vista da análise dos dados e observações, que o material bibliográfico nos polos, comparado à bibliografia básica dos cursos, não atendem às demandas necessárias dos usuários e o ideal de uma biblioteca com seus recursos informacionais. Em relação aos recursos humanos, foi observado que falta o profissional bibliotecário; e em relação à infraestrutura uma das bibliotecas do polo não possuía o mínimo necessário de espaço físico e equipamento, o que foi resolvido, após serem apresentados os resultados da pesquisa.

As conclusões são semelhantes aos resultados obtidos no estudo de usuários, quando 43\% dos respondentes disseram não utilizar a biblioteca, sendo estes uns dos motivos pelos quais não a utilizam: "Pobre em livros e atendimento"; "Não possui os livros que preciso"; "Falta material"; "Não tem livros suficientes para a demanda de alunos"; "Até o último encontro presencial no Polo, não sabia da existência da Biblioteca". Ainda assim, dos respondentes, $57 \%$ disseram que utilizam a biblioteca do polo (COSTA, 2015).

Sobre os serviços e produtos informacionais oferecidos pelas bibliotecas do SB/UFMG e que podem ser estendidos aos usuários da modalidade a distância, estão as Bases de Dados, Biblioteca Digital de Teses e Dissertações, Catálogo on-line da Biblioteca - Pergamun, Serviço de COMUT, o Portal de Periódicos da Capes, Carteira de Usuário e o Empréstimo domiciliar do material bibliográfico do SB/UFMG. No entanto, a porcentagem de 
conhecimento, pelos alunos da EaD, das fontes de informação, serviços e produtos são relativamente baixas. De acordo com Costa $(2015$, p. 53) no estudo de usuários respondentes mostraram um alto grau de interesse em participar de treinamento e receber orientações sobre os serviços informacionais disponibilizados para os mesmos. De acordo com Tozoni-Reis (2007), é preciso articular a produção de conhecimentos, ação educativa e participação, numa perspectiva necessariamente transformadora da realidade.

Ainda de acordo com a metodologia da pesquisa qualitativa, a pesquisadora observou que nos polos há grandes entusiastas do ensino a distância mostrando-se esforço no desempenho das funções e boa vontade em levar a educação a distância à frente, podendo ser observado no desempenho dos coordenadores desses polos e suas equipes. Isso já é um grande fator para que, principalmente, nos polos haja apoio aos alunos, considerando principalmente que de acordo com o MEC, "os polos são uma extensão da Universidade". A partir dessas análises, são necessárias políticas públicas e ações das instituições envolvidas, para verificar junto a estas as competências de cada uma. Dessa forma, as organizações envolvidas, como as prefeituras dos municípios em parcerias com as instituições educacionais responsáveis pelo ensino, deverão atuar para que o aluno receba todos os recursos informacionais necessários à sua formação acadêmica.

As bibliotecas universitárias responsáveis pelo provimento de informações aos alunos precisam buscar soluções e criar diretrizes com regulamentos, normas e manuais, para o atendimento dos alunos nas bibliotecas dos polos, atuando em parcerias com as instituições envolvidas. “O planejamento de serviços de biblioteca para o aprendizado a distância [deve] ser orientado pelo seguinte princípio: o que é bom para os alunos no campus também deve ser bom para os alunos a distância". (MOORE; KEARSLEY, 2008, p.210).

Sabe-se que num país como o Brasil, mesmo com a evolução da educação a distância, há muito ainda a ser feito. É um país populoso, gigante, e com grande diversidade sociocultural. Nesse sentido, a educação a distância tem contribuído para levar o ensino no interior do nosso país, democratizando o acesso do povo brasileiro à educação.

Assim sendo, pode-se inferir que cada um precisa fazer a sua parte, cada um dos envolvidos nesse processo, para o avanço e beneficio da sociedade, a sociedade da informação; a sociedade do conhecimento, no sentido de proporcionar a ela o acesso à educação, (in) formando uma sociedade mais humanizada, mais escolarizada, e, portanto, uma sociedade com mais conhecimento, caminhando para uma sociedade mais igualitária. Assim se faz o desenvolvimento de uma nação, como cita Takahashi (2000, p. 45), quando diz que na Sociedade da Informação, a educação é vista como "o elemento-chave na construção de uma sociedade baseada na informação, no conhecimento e no aprendizado".

\section{AGRADECIMENTOS}

Ao Professor Wagner José Corradi Barbosa, diretor do Centro de Apoio a Educação a Distância-CAED/UFMG, pelo apoio a pesquisa. 
Ao Professor Fernando Fidalgo diretor do Centro de Apoio a Educação a Distância- CAED/UFMG, e Professor José Corradi Barbosa - Vice-diretorCAED/UFMG, pelo apoio a pesquisa (na época da pesquisa).

\section{REFERÊNCIAS}

ASSOCIATION OF COLLEGE AND RESEARCH LIBRARIES - ACRL. Guidelines for Distance Learning Library Services. [Washington]: ALA/ACRL, 1998.

BLATTMANN, U. Modelo de gestão da informação digital on-line em bibliotecas acadêmicas na educação à distância: biblioteca virtual. Tese, Universidade Federal de Santa Catarina, Florianópolis, SC, Brasil, 2001. Disponível em: <http://eprints.rclis.org/9976/1/Ursula Dr.pdf>. Acesso em: 21 abr. 2012.

BRASIL. Blog do Planalto. Brasília, 2011. Disponível em: <http://blog.planalto.gov.br/assunto/escolas-tecnicas/>. Acesso em: 23 nov. 2012.

BRASIL. Ministério da Educação. Lei n. 9.394 de 20 de dezembro de 1996. Estabelece as diretrizes e bases da educação nacional. Diário Oficial da União, Brasília, DF, 1996. Disponível em: <http://portal.mec.gov.br/seed/arquivos/pdf/tvescola/leis/lein9394.pdf>. Acesso em: 06 jul. 2012.

BRASIL. Ministério da Educação. Decreto n. 5.622 de 19 de dezembro de 2005.Regulamenta o Art. 80 da Lei no 9.394, de 20 de dezembro de 1996, que estabelece as diretrizes e bases da educação nacional. Diário Oficial da União, Brasília, DF, 20 dez. 2005. Disponível em: <http://portal.mec.gov.br/sesu/arquivos/pdf/portarias/dec5.622.pdf>. Acesso em: 10 set. 2012.

BRASIL. Ministério da Educação. Decreto n. 5.773 de 9 de maio de 2006. Dispõe sobre o exercício das funções de regulação, supervisão e avaliação de instituições de educação superior e cursos superiores de graduação e sequenciais no sistema federal de ensino. Diário Oficial da União, Brasília, DF, 2006. Disponível em:

$<$ http://portal.mec.gov.br/seed/arquivos/pdf/legislacao/decreton57731.pdf >. Acesso em: 09 jun. 2012.

BRASIL. Ministério da Educação. Secretaria de Educação a Distância.

Referenciais de qualidade para educação superior a distância. Brasília, 2007. Disponível em: <http://portal.mec.gov.br/seed/arquivos/pdf/legislacao/refEaD1.pdf>. Acesso em: 12 abr. 2012.

BRASIL. Ministério da Educação. Universidade Aberta do Brasil. 20122013. Disponível em: <http://www.uab.capes.gov.br/>. Acesso em: 07 abr. 2012. 
COSTA, M. E. O. et. al. Sistema de bibliotecas da UFMG: criação de um setor de apoio às bibliotecas polos da EaD. In: SEMINÁRIO NACIONAL DE

BIBLIOTECAS UNIVERSITÁRIAS, 17, 2012, Gramado. Anais... Gramado: UFRS, 2012. p. 1-12. Disponível em:

<http://www.snbu2012.com.br/anais/pdf/4REK.pdf $>$. Acesso em: jan., 2013.

COSTA, M. E. 0; Santos, Marizete; Barbosa, Anderson L. Rocha. Educação a distância e as bibliotecas universitárias: uma interação necessária.

Perspectivas em Ciência da Informação, Belo Horizonte, v.20, n.2, p.38-57. Disponível em: <http://www.scielo.br/pdf/pci/v20n2/1413-9936-pci-2002-00038.pdf> Acesso em: 12 jun. 2015.

DUARTE, V. M. do N. Pesquisas: exploratória, descritiva e explicativa. [2013?]. Monografias Brasil Escola. Disponível em:

$<$ http://monografias.brasilescola.com/regras-/pesquisas-exploratoriadescritiva-explicativa.htm>. Acesso em: 17 set. 2012.

FERRUGINI, L et al; Educação a distância no Brasil: potencialidades e fragilidade. Revista da Universidade Vale do Rio Verde, Três Corações, v. 12, n. 1, p 90-98, jan./jul. 2014.

FRANCO, M. A. S. Pedagogia da pesquisa-ação. Educação e Pesquisa, São Paulo, v. 31, n. 3, p. 483-502. set./dez. 2005.

GARCEZ, E. M. S.; RADOS, G. J. V. Biblioteca híbrida: um novo enfoque no suporte à educação a distância. Ciência da Informação, Brasília, v. 31, n. 2, p. 44-51, maio/ago. 2002.

GARCEZ, E. M. S.; RADOS, G. J. V. Necessidades e expectativas dos usuários na educação a distância: estudo preliminar junto ao Programa de Pós-Graduação em Engenharia de Produção da Universidade Federal de Santa Catarina.

Ciência da informação, Brasília, v. 31, n. 1, p. 13-26, jan./abr. 2002.

GIL, A. C. Como elaborar projetos de pesquisa. 4. ed. São Paulo: Atlas, 2002.

KETELE, J.; ROEGIERS, X. Méthologie du recueil d'informations: fondements de méthodes d'observation de questionaires, d'interviews et d'étude de documents. 2. ed. Bruxelles: De Boeck Universisté, 1993.

KONRATH, M. L. P.; TAROUCO, L. M. R.; BEHAR, P. A. Competências: desafios para alunos, tutores e professores da EaD. RENOTE: Revista Novas

Tecnologias na Educação, Porto Alegre, v. 7, n. 1, jul., 2009.

LITTO, Fredric Michael. 0 atual cenário internacional da EaD. In: LITTO, Fredric; FORMIGA, Marcos. Educação a distância: o estado da arte. São Paulo: Pearson Education do Brasil, 2009. p. 14-20. 
MACEDO, N. D. de; MODESTO, F. Equivalências: do serviço de referência convencional a novos ambientes de redes digitais em bibliotecas. Revista Brasileira de Biblioteconomia e Documentação, São Paulo, v. 1, n. 1, p. 38$72,1999$.

MENDES, D. de S. Luz, câmera e pesquisa-ação: a inserção da mídia educação na formação contínua de professores de Educação Física. 2008. Dissertação (Mestrado em Educação Física) - Centro de Desportos, Universidade Federal de Santa Catarina, Florianópolis, 2008. Disponível em: <http://www.eps.ufsc.br/disserta98/roser/index.htm>. Acesso em: 09 ago. 2012.

MINAYO, M. C. S. (Org.). Pesquisa social: teoria, método e criatividade. 22. ed. Petrópolis, RJ: Vozes, 1994.

MINAYO, M. C. S. 0 desafio do conhecimento científico: pesquisa qualitativa em saúde. 2. ed. São Paulo: Hucitec-Abrasco, 1994.

MOORE, M. G.; KEARSLEY, G. Educação a distância: uma visão integrada. São Paulo: Thomson Learning, 2007.

TARQUINIO, M. V.; SILVEIRA, M. M. G. da; OLIVEIRA, R. B. de. Panorama da institucionalização da EaD na UFMG. In: FIDALGO, F.; FIDALGO, N.; NEVES, I. de S. V. (Org.). Educação a distância: tão longe, tão perto. Belo Horizonte: Centro de Apoio à Educação a Distância/UFMG, 2012. cap. 5, p. 135-154.

TAKAHASHI, T. (Org.). Sociedade da Informação no Brasil: o livro verde. Brasília, DF: Ministério da Ciência e Tecnologia, 2000.

TOZONI-REIS, M. F. de C. A pesquisa-ação-participativa em educação ambiental: reflexões teóricas. São Paulo: Annablume, 2007.

TRIP, D. Pesquisa-ação: uma introdução metodológica. Educação e Pesquisa, São Paulo, v. 31, n. 3, p. 443-466, set./dez. 2005.

UNIVERSIDADE FEDERAL DE MINAS GERAIS - UFMG. Biblioteca Universitária. Disponível em: <https://www.bu.ufmg.br/cont hist.htm>. Acesso em: 23 out. 2012.

UNIVERSIDADE FEDERAL DE MINAS GERAIS - UFMG. Centro de Apoio à Educação a Distância - CAED, 2012. Disponível em:

<http://www.ufmg.br/ead/site/>. Acesso em: 11 abr. 2012. 